\title{
SOCIAL LEARNING: THE KEY TO INTEGRATED WATER RESOURCES MANAGEMENT?
}

E. Mostert, M. Craps, C. Pahl-Wostl

\begin{abstract}
This article discusses social learning as a means to implement integrated water resources management (IWRM). Implementing IWRM requires cooperation between policy sectors, countries, government bodies, the civic sector and scientific disciplines. The social learning approach suggests several ingredients for such cooperation. First, water managers and the other stakeholders need to realize their dependence on each other for reaching their own goals. Next, they need to start interacting, share their problem perceptions and develop different potential solutions. This requires the development of mutual trust, recognition of diversity and critical self-reflection. Finally, the stakeholders need to take joint decisions and make arrangements for implementation. Often, an external facilitator can be helpful. The social learning approach to IWRM has several implications for the IWRM ToolBox of the GWP. Social learning is not a magic solution for all problems, but there is sufficient evidence that it can work.
\end{abstract}

\section{Keywords:}

Integrated water resources management, social learning, cooperation, transboundary

\section{Introduction}

Readers of Water International cannot have missed the discussion on Integrated Water Resources Management (IWRM) initiated by Asit K. Biswas (Biswas 2004a, b). IWRM has been defined as "a process which promotes the co-ordinated development and management of water, land and related resources, in order to maximize the resultant economic and social welfare in an equitable manner without compromising the sustainability of vital ecosystems." (GWP 2000) According to Biswas, this definition is very vague and impossible to put into practice. According to others, 
however, the IWRM concept has had a positive effect on water management and research (Dukhovny 2004, Lamoree 2004, Mitchell 2004, Nickum 2005).

Beneath the disagreement, there is in fact a lot of agreement. All protagonists recognize the central importance of boundaries in water management. These include:

- "physical" boundaries between surface and groundwater, water quantity and quality, freshwater and coastal waters, water resources and land resources, different geographical scales and different time scales

- $\quad$ administrative boundaries between different countries, government levels and policy sectors

- $\quad$ social boundaries between different social and economic groups (Prins et al. 2006) and between these groups and government

- $\quad$ cognitive boundaries between different disciplines, between technical experts and "lay experts" (cf. Scheer 1996, Lorraine et al. 2005) and between different lay experts

The main disagreement revolves around the issue how to manage these boundaries. According to Biswas (2004a), IWRM would imply the concentration of all waterrelated tasks and responsibilities in the water sector. In practice, this would not be feasible because of opposition from other sectors such as the energy sector, which would lose tasks and responsibilities. Moreover, it would make the other sectors less integrated. The resulting IWRM-bodies would be very large and bureaucratic and sectoral interests would be less well represented (cf. Viessman 1997, Hooper et al. 1999, Mitchell 2005).

A more sophisticated concept of IWRM recognizes that there will always be boundaries and that the key to IWRM is cooperation across boundaries (e.g. Mitchell 1990, Margerum and Born 1995, Viessman 1997, Hooper et al. 1999, Margerum 1999, Mostert et al. 2000, Bouwen and Taillieu 2004, Falkenmark et al. 2004, GWP 2005, Prins et al. 2006). One approach that can help to realize cooperation across boundaries is social learning. 
This article presents the social learning concept as developed in the European HarmoniCOP project (Box 1). It discusses the key ingredients of social learning and presents some practical experiences. Moreover, it discusses the implications for IWRM. It does so in the form of a review of the Global Water Partnership's IWRM ToolBox (GWP 2005).

The HarmoniCOP-project was set up in the framework of the $5^{\text {th }}$ European

Framework Programme for Research and Technological Development and involves 17 institutes from nine European countries. It aimed to increase the understanding of participatory river basin management against the background of the European Water Framework Directive. In the project a literature study on social learning has been made (Craps 2003) and ten case studies have been conducted (Tippett et al. 2005). Moreover, a handbook for practitioners has been prepared, titled "Learning together to Manage Together; Improving Participation in Water Management" (Ridder et al. 2005). More detailed analyses and case study descriptions will be published in a special issue of Ecology and Society. All project reports can be found at the project's website: www.harmonicop.info.

Box 1: The HarmoniCOP project

\section{The social learning concept}

Social learning can be summarized as learning together to manage together (Craps 2003, Ridder et al. 2005). It means learning by all stakeholders, governmental and non-governmental, to manage the issues in which they have a stake. Typically, no one has all the legal competencies, funds, information and other resources that would be necessary to manage these issues to his own satisfaction. Consequently, the stakeholders need to cooperate and pool resources.

Suppose, for example, that a water manager wants to construct a flood retention basin. For this he may need financial resources from the treasury and authorizations from the land-use planning authorities. All need sufficient support from the public to prevent political complications and litigation. To develop a basin that is acceptable to all, 
different concerns need to be incorporated in the design, such as landscape, nature and recreation. This requires cooperation between different experts.

Social learning takes place within a context (cf. Hooper et al. 1999, Shah et al. 2001, see Figure, Ison et al. 2004). This includes the governance system, economy and culture (social context) and the hydrological and geographical conditions (natural context). Together, they determine who the main stakeholders are and what they see as the main management issues (Figure 1).

Figure 1: Outline of the social learning process

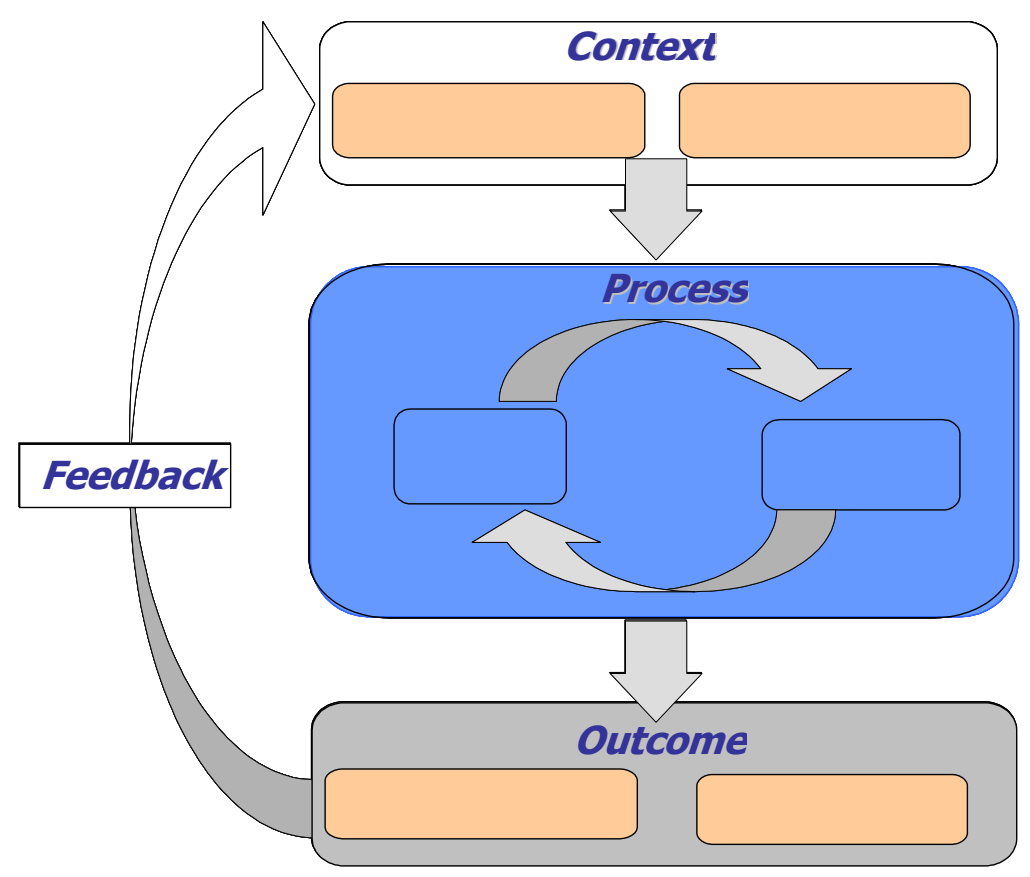

Social learning implies that the different stakeholders learn to resolve these issues (content management). To do so, they have to relate to each other (social involvement). They have to come to a shared understanding of the problems at stake and the system to be managed, agree on a solution and ensure that the solution is implemented.

The outcome of social learning is water management that better serves the interests of all stakeholders (technical qualities). Moreover, stakeholders may feel more involved, new skills may be acquired, new knowledge and insights may be obtained, trust may develop, relations may improve and institutions may change (relational qualities). 
This, in turn changes the natural context and may improve management capacity (feedback).

Central to social learning are framing and re-framing processes. Framing refers to how people see reality. An engineer, for instance, can view a specific river basin quite differently than an ecologist or a lawyer, and he or she will view it differently than an environmentalist or a farmer. They perceive different aspects of the basin, construct a different image of how it functions, observe different problems, view the other stakeholders differently and perceive different solutions. They "cut out" different slices of reality. This is the result of their specific experiences and of the different frames that they use to make sense of these experiences (Bouwen et al. 1999, Dewulf et al. 2005a, Dewulf et al. 2005b). Examples of frames in water management include the development versus the protection frame (cf. World Commission on Dams 2000), the privatization frame (e.g. World Bank 1997) and many disciplinary frames (e.g. Mostert 1999).

When stakeholders use different frames, they are unlikely to agree on the issues at stake and on their solution. This requires reframing. The stakeholders need to recognize each other's frame and enrich their own frame, in order to develop a common ground for cooperation.

Reframing may also be necessary when all stakeholders use the same frame. For instance, a common frame in transboundary river basin management is sharing (scarce) water. In this frame, one country's gain is another country's loss. An alternative frame is benefit sharing. This frame draws attention to the benefits that can be derived from the water and turns transboundary river basin management into a win-win game, with better prospects of a mutually satisfactory agreement (Sadoff and Grey 2002, Klaphake 2005).

The social learning concept presented here differs fundamentally from the wellknown work by Bandura (1977). His concept of social learning refers to individual learning based on imitation of role models. This is an important learning mechanism, but insufficient for getting better water management (see on social learning also Bouwen and Taillieu 2004, Ison et al. 2004, The SLIM Project 2004). 


\section{Elements of social learning}

Social learning processes differ from case to case, but they have a number of elements in common:

\section{Recognition of interdependence}

Social learning requires that the stakeholders recognize their interdependence. The water authorities need to become aware that they cannot impose any policy they like, for instance, because others have to implement it, funds from the private sector are needed or control and enforcement is difficult. Industries need to show a minimum level of environmental awareness to prevent that public opinion turns against them and regulation becomes more strict and oppressive. Experts may need to realize that they lack detailed local knowledge that the local inhabitants may have. The exact interdependencies differ from case to case, but usually there are many.

\section{Interaction between all stakeholders}

Social learning requires interaction. This can take place in so-called "communities of practice": small groups of people involved in the same tasks that interact directly (Wenger 1998). Examples include working groups, water users' associations and river basin commissions (see also Margerum 1999, Leach and Pelkey 2001, Warner 2006).

Important issues are who are the stakeholders and how to deal with large numbers of stakeholders. There are no easy answers to these questions. On the one hand, the issues at stake determine the stakeholders that should be involved, but at the same time the stakeholders involved determine what the issues are. If there are many stakeholders and stakeholder groups, use has to be made of representatives and/ or working group and subcommittee structures. An important issue is the interaction between working groups and between representative and their constituencies, especially in the case of heterogeneous constituencies.

\section{Trust}


Stakeholders will only start interacting if they trust that they can reach an agreement that serves their interests better than unilateral action (e.g. litigation) and will actually be implemented (Gray 1989). They need to trust that the other stakeholders are willing to cooperate and will honour their side of an agreement. But trust is not a given. Trust can be developed by postponing any commitment (cf. Bruijn et al. 2002) and starting with non-controversial issues, such as data exchange and joint research (Dieperink 1997, Savenije and Zaag 1998, Dieperink 1999, Leach and Pelkey 2001, Nicol 2003). This moreover results in a common factual basis for further cooperation.

\section{Respect of diversity}

Different stakeholders have different interests, views and information. This can create problems that need to be discussed (cf. Vansina and Taillieu 1997, Margerum 1999), but it can also be a source of strength. Different views and information can complement and enrich each other and different interests can provide opportunities for mutually beneficial exchanges.

\section{Critical self-reflection}

Interaction may result in a stalemate or in a mere compromise. To reach an agreement that is beneficial for all stakeholders, a lot of self-reflection is needed. Firstly, all participants need to reflect on their own position and goals. These may not be the most effective for achieving what they really value. In addition, some flexibility with respect to these increases the chance of an agreement (cf. Fisher and Ury 1981). Secondly, the participants need to reflect on their assumptions concerning the system to be managed. These may not be correct. And thirdly, the participants need to reflect on how their actions affect the actions of the other participants. If they do not do this, negative stereotypes and unconstructive behavioural patterns may develop (cf. Argyris and Schön 1996).

\section{Exchange of problem perceptions}

If the stakeholders do not agree on the problem or problems at stake, they are unlikely to agree on the solution. Consider for instance a plan for dyke reinforcement. For a water manager this might solve his problem meeting statutory safety standards. For environmental NGOs, however, the plan may constitute a threat to the habitat of an endangered species, and people living on the dyke may be forced to move. If the 
water manager imposes his problem perception, the result will be either a dyke with many negative side-effects or no dyke at all because of strong public opposition.

Much more satisfactory results are possible if the different stakeholders recognize each other's interests. Alternatives can then be developed that provide the same or nearly the same benefits but with fewer or no negative side effects (e.g. a different dyke design or non-structural flood protection measures) (cf. Pahl-Wostl 2006). This requires critical self-reflection. Recognition of other interests should go hand-in-hand with a willingness to move away from original positions.

\section{The development and critical assessment of potential solutions}

Social learning always involves the development and critical assessment of potential solutions. It has been argued by Fisher and Ury (1981) that more than two alternatives should be considered as this would decrease the chance of polarization and positional bargaining and increase the chance of an integrative solution. The assessment of the alternatives should be based on a sound system understanding (Margerum 1999, Leach and Pelkey 2001).

\section{Joint decision-making, based on reciprocity and commitment}

Eventually, one alternative has to be chosen and implemented. All stakeholders need to commit themselves to take certain actions (and refrain from others). This in turn requires joint decision-making and reciprocity. To obtain the cooperation from the other stakeholders, each stakeholder needs to give in on points that are of less importance to him or her. In this way all stakeholders may benefit.

\section{Arrangements to promote implementation}

Decisions often have to be implemented by others. Water treaties, for instance, are usually concluded by national government representatives, but they need to be ratified by parliament or the cabinet and implemented by lower-level government bodies. Representatives need a broad mandate to be able to collaborate effectively, but they need to keep their constituencies informed and maintain their trust to prevent problems later on. It may be useful to establish temporary or permanent organizations for monitoring implementation and renegotiating agreements when necessary (cf. 
Gray 1989). River basin commissions often perform this function (Burchi and Spreij 2003).

\section{Facilitating social learning}

Social learning is not something new. It happens whenever people from different backgrounds and with different interests and resources come together and manage to everybody's satisfaction an issue in which all have a stake. Social learning often occurs without any external assistance. The initiative for social learning can come from a water manager who experiences a problem or sees a potential for cooperation, or from one of the other stakeholders.

SL requires crossing boundaries and bridging differences. This often goes against our social and cultural intuitions. External facilitation may be helpful. By facilitation we mean interventions that are focussed on the social process among the stakeholders involved to support constructive interactions." (Gray 1989, Leach and Pelkey 2001, Bruijn et al. 2002, Ridder et al. 2005). It includes convening the major stakeholders, structuring the process, selecting methods and tools (workshops, interactive modelling, etc.) and facilitating meetings.

The major task for facilitators is to promote the nine elements discussed in the previous section. More concretely, they can help the other stakeholders to:

1. explore interdependencies, e.g. in bilateral talks or through a form of participatory stakeholder analysis

2. establish contact, e.g. by offering neutral meeting facilities or acting as intermediary

3. foster trust, e.g. by challenging stereotypes or discussing the effects of less constructive types of behaviour

4. recognize the benefits of diversity

5. promote critical self-reflection, e.g. by asking critical questions that make the stakeholders think

6. elicit and explore different problem perceptions 
7. develop and assess different potential solutions, e.g. by discussing the effects of the different solutions and suggesting new solutions

8. take joint decisions, e.g. by designing procedures, discussing the benefits for the different parties and proposing mutually beneficial exchanges

9. implement the decision by discussing and proposing specific arrangements to that end.

Facilitators may offer special support to stakeholders that are less well endowed with verbal skills, financial resources and other resources (Craps et al. 2004). This may be in the interest of the stronger stakeholders too. Special support enables the less well endowed stakeholders to influence the outcome of the process more. This promotes that they enter and stay in the process, commit themselves to the outcome and do not opt for more confrontational strategies.

An important issue is who should take on the role of facilitator. Facilitation requires a lot of technical and social expertise. Especially the latter may not be available in water management bodies. Even if it is, it may be advisable to hire an external facilitator because facilitation works best if the facilitator is seen as impartial.

It is important to note that social learning cannot be imposed by government, it can only be supported and facilitated. Moreover, it requires space. The outcome cannot be predetermined, but is determined in the process. Still, government remains a special stakeholder, with special responsibilities and competencies (regulation). A social learning approach can help government to perform its role more effectively (Klijn and Koppenjan 2000, Bruijn et al. 2002).

Moreover, social learning processes are resource and time intensive, both for water managers and for the other stakeholders. They should therefore only be embarked upon concerning issues that are both important and complex and when the necessary resources and time can be made available (cf. Hooper et al. 1999, Margerum and Whitall 2004). 


\section{Experiences with social learning}

Social learning is an approach or "frame" for analysing and promoting collaboration. To increase our understanding of how this approach can function, ten case studies on participatory river basin management were conducted in the HarmoniCOP project (Rees et al. 2005, Tippett et al. 2005). In several cases new contacts between the stakeholders were made or existing contacts were reinforced and trust improved. In two cases -the Dordogne basin (France) and the Muga basin (Spain) - a new river basin organization was established (Barraqué et al. 2004, Tàbara et al. 2004).

Moreover, quite a lot of reframing took place, resulting in improvements for all stakeholders concerned. In the Bacchiglione Basin (Italy), local stakeholders initially objected strongly to a proposal to relocate a wastewater discharge outlet. In response to these objections, the authorities involved the local stakeholders. This enabled the local stakeholders to increase their understanding of water quality problems and develop a basin wide perspective. They also became more receptive to solutions proposed by the authorities (Massarutto et al. 2004). In the Dee Basin (Scotland), the local authorities put forward a proposal for a wastewater treatment plant to comply with European legislation. Due to the contentious nature of the proposal, the local community was invited to become involved in the process. This resulted in the development of solutions that the authorities had not previously considered, such as the inclusion of wetlands. The initial proposal was reframed, enabling an increase in amenity values, water quality and biodiversity within the area and greater ownership of the solutions developed.

The case studies also identified a number of obstacles to social learning. Quite often the existing governance style was not participatory and it took a lot of convincing to move towards a more collaborative approach. In many cases the authorities lacked experience with multi-party approaches, relied heavily on technical expertise, were not willing to change, feared to loose control or feared that too broad participation could threaten the confidentiality of proceedings (Rees et al. 2005, Tippett et al. 2005). Other obstacles to social learning include a history of mistrust, fundamental ideological differences and large differences in resources (Gray 1989). 
The cases show that social learning is not a simple technique for solving all water management problems. Social learning processes always need to be adapted to the evolving context, which may not always be very conducive to social learning. Yet, in cases of mutual interdependence, social learning is the only satisfactory approach in the long run. There are several cases where social learning did work, including cases where interests conflicted and relations were initially mediocre or absent (Craps et al. 2004).

\section{Implications}

The social learning approach has several implications for the implementation of IWRM. To aid implementation of IWRM, the Global Water Partnership has developed the IWRM ToolBox (GWP 2005). The ToolBox contains some 50 tools, which in different combinations are meant to solve a wide range of water management problems. This section will review the main categories of tools from the ToolBox.

\section{Policies and plans}

Policies and plans concerning IWRM include water policies and plans as well as other policies and plans relevant for water resources, such as land use plans. In a social learning approach, policy development and planning should not be exclusively governmental activities - at least not if they are to make a difference in practice. Instead, they should be a shared responsibility and contain the nine elements outlined in section 3. This requires active involvement of the major stakeholders, moving far beyond mere public consultation. It also requires that water managers do not impose their frame to the exclusion of all other frames. The frames of all stakeholders should be considered and discussed.

\section{Legislative framework and regulatory instruments}

The relation between legislative frameworks and regulatory instruments on the one hand and social learning on the other is quite complex. Legislative frameworks and regulatory instruments can influence the outcome of social learning processes by strengthening the position of some stakeholders and by prescribing or forbidding 
certain types of action. However, regulations are not self-executing and control and enforcement is often very difficult. Detailed substantive rules can frame the issues too much and foreclose promising solutions. Stakeholders may then loose interest in the process and may not want to commit themselves. Detailed procedural rules can constrain the social learning process itself.

\section{Financing, incentive structures and economic instruments}

Social learning implies that decision-making should involve those who have to provide the finances for implementing the decision. It can be argued that social learning is promoted most if financing and decision-making structures are simple and transparent and responsibility for both are combined in one hand, at the lowest possible level.

\section{Organizational frameworks}

Very complex organizational frameworks and unclear and highly overlapping competencies can result in competency struggles and increase the number of stakeholders unnecessarily. Reorganizations may be needed, but they are timeconsuming and use up a lot of energy without a guarantee of success. Moreover, they do not solve all problems. As argued in the introduction, combining all relevant competencies and resources in one hand is impossible.

\section{Building institutional capacity}

Institutional capacity building for IWRM in a broad sense refers to everything that is needed for putting IWRM into practice: individual skills, appropriate organizational and legal frameworks, policies and plans, monitoring, etc. (cf. CAP-NET 2002, Hooper 2005). In the ToolBox two tools are discussed under this heading: "Participatory capacity and empowerment in civil society" and "Training to build capacity in water professionals". As to the latter, important skills for water professionals include social skills and facilitation skills, in addition to technical skills.

\section{Water resources assessment and information exchange}

In social learning terms, water resources assessment plays a crucial role for content management and for achieving outcomes with high technical qualities. But there are some differences with traditional water resources assessment. Water resources 
assessment should not be the exclusive realm of experts. Experts can never be completely objective. What they study and how they interpret and present the results is influenced by their disciplinary and organizational background and by the wishes of their client or clients (usually government bodies). Involving different stakeholders in setting terms of reference for research and supervising the research can help to make the research more relevant and more acceptable for them (cf. Margerum and Whitall 2004).

Moreover, water resources assessment should make full use of the information from lay persons. Lay persons are in fact experts as well, but their expertise is of a different kind (Lorraine et al. 2005). Lay persons have a lot of practical, concrete expertise concerning their daily affairs (e.g. farming) and have amassed a lot of concrete local knowledge about the current situation (e.g. about soil conditions). Scientific experts, on the other hand, possess more abstract, formal and non-localized knowledge and can apply scientific and technical theories and approaches for predicting or designing future situations. In theory, scientific and "lay experts" can complement each other (Scheer 1996). In practice, however, lay expertise is often not recognized and scientific experts may feel that their competence and integrity is challenged if their knowledge is not accepted unconditionally.

\section{Efficiency in water use}

Efficiency in water use is an important goal of IWRM. It is not a goal of social learning, but in situations of water scarcity increasing water use efficiency can be an important means for satisfying the interests of the different water users as much as possible. The difference is subtle. The point is that water management is often most effective if you start at the beginning - the stakeholders and their concerns - and not with goals or solutions.

\section{Social change instruments}

According to the IWRM ToolBox, IWRM requires changes of deeply held attitudes in individuals, institutions, professionals and social organizations. Instruments would include changing school curricula, communication with stakeholders and awareness raising through information and transparency. The social learning concept suggests that social change may be most effective if people are allowed to change themselves 
and the final end-state is not set for them by others (water managers, experts, ...). Successful social learning processes allow the different stakeholders to better shape their own destiny.

\section{Conflict resolution}

Conflicts are often analysed in terms of interest rather than in terms of frames. Social learning emphasizes the need to analyse frames and to facilitate reframing. Conflict may not be resolved if frames are ignored and reframing is lacking.

\section{Conclusion}

The social learning approach can help to overcome the boundaries between different types of water management (surface water management, groundwater management, etc.), between the water sector and other policy sectors, between government and the public and between different disciplines. The key is cooperation across boundaries. The social learning approach lists nine essential ingredients for such cooperation and suggests ways to facilitate cooperation. The social learning approach does not provide solutions for concrete water management problems, but it suggests how the stakeholders themselves can develop effective solutions to everybody's satisfaction.

Social learning can be said to be the key to implementing IWRM, but there is still a lot to learn. As stated before, social learning is essentially a frame for analyzing and promoting collaboration. More experience needs to be gained with using this frame, to find out how effective it is compared to other frames and to refine it for making it more effective. The best way forward is action research: research in and with the practice.

\section{Authors Bios}

Erik Mostert teaches water law and integrated water management at the Delft university of Technology. His research includes public participation, transboundary water management and institutions for river basin management. 
Address: RBA Centre, Delft University of Technology, Stevinweg 1, 2628 CN Delft, The Netherlands. E-mail e.mostert@citg.tudelft.nl.

Marc Craps is lecturer at the VLEKHO Business School in Brussels and researcher at the Centre for Organizational and Personnel Psychology, Katholieke Universiteit Leuven (Belgium). His teaching and research activities focus on multiparty collaboration, social learning and sustainable natural resources management. Address: Tiensestraat 102, B-3000 Leuven, Belgium, E-mail:

Marc.Craps@psy.kuleuven.be

Dr. Claudia Pahl-Wostl is professor for the 'Management of Resource Flows', an endowed chair of the German Environmental Foundation at the Institute of Environmental Systems Research, University of Osnabrck. She co-ordinated the HarmoniCOP project and presently co-ordinates the NEWATER project (New methods for adaptive water management).

Address: Inst. for Environmental Systems Research, University of Osnabrück, Barbarastrasse12, 49069 Osnabrück, Germany, E-mail: pahl@usf.uni-osnabrueck.de

\section{ACKNOWLEDGEMENTS}

The work of the HarmoniCOP project presented in this paper has been financially supported by the European Commission under the contract number EVK1-CT-200200120.

\section{REFERENCES}

Argyris, C., and D. Schön. 1996. Organizational Learning II. Theory, Method and Practice. Addison-Wesley, Reading, Massachusetts.

Bandura, A. 1977. Social learning theory. Prentice Hall, Englewood Cliffs, N.J.

Barraqué, B., J. P. Le Bourhis, P. Maurel, and R. Raymond. 2004. Participation and Social Learning in the Dordogne River Basin France. LATTS-CNRS, Paris. 
Biswas, A. K. 2004a. Integrated Water Resources Management: A Reassessment. Water International 29:398-405.

Biswas, A. K. 2004b. Response to Comments by Mitchell, Lamoree, and Dukhovny. Water International 29:398-405.

Bouwen, R., M. Craps, and E. Santos. 1999. Multi-party Collaboration. Building Generative Knowledge and Developing Relationships among 'Unequal' Partners in Local Community Projects in Ecuador. Concepts and Transformation 4:133-151.

Bouwen, R., and T. Taillieu. 2004. Multiparty Collaboration as Social Learning for interdependence: Developing Relational Knowledge for Sustainable Natural Resources Management. Journal of Community and Applied Social Psychology 14:137-153.

Bruijn, H. d., E. ten Heuvelhof, and R. in 't Veld. 2002. Process management; Why project management fails in complex decision making processes. Kluwer Academic, Dordrecht.

Burchi, S., and M. Spreij. 2003. Institutions for International Freshwater Management. Unesco, Paris.

CAP-NET. 2002. Capacity Building for Integrated Water Resources Management; The importance of Local Ownership, Partnerships and Demand Responsiveness.

Craps, M., editor. 2003. Social learning in river basin management; HarmoniCOP WP2 reference document. K.U. Leuven-COPP, Leuven.

Craps, M., A. Dewulf, M. Mancero, E. Santos, and R. Bouwen. 2004. Constructing Common Ground and Re-creating Differences Between Professional and Indigenous Communities in the Andes. Journal of Community \& Applied Social Psychology 14:378-393.

Dewulf, A., M. Craps, R. Bouwen, T. Taillieu, and C. Pahl-Wostl. 2005a. Integrated management of natural resources: dealing with ambiguous issues, multiple actors and diverging frames. Water Science \& Technology 52:115-124.

Dewulf, A., B. Gray, L. Putnam, N. Aarts, R. Lewicki, R. Bouwen, and C. v. Woerkum. 2005b. Disentangling approaches to framing: mapping the terrain. in 18th IACM Conference, Seville, 12-15 June 2005.

Dieperink, C. 1997. Tussen zout en zalm lessen uit de ontwikkeling van het regime inzake de Rijnvervuiling. Thesis Publishers, Amsterdam. 
Dieperink, C. 1999. From Open Sewer to Salmon Run: Lessons From the Rhine Water Quality Regime. Water Policy:471-485.

Dukhovny, V. 2004. Integrated Water Resources Assessment: A Reassessment by Asit K. Biswas. Water International 29:398-405.

Falkenmark, M., L. Gottschalk, J. Lundqvist, and P. Wouters. 2004. Towards Integrated Catchment Management: Increasing the Dialogue between Scientists, Policy-makers and Stakeholders. Water Resources Development; International Journal of Water Resources Development 20:297-309.

Fisher, R., and W. Ury. 1981. Getting to yes: negotiating agreement without giving in. Houghton Mifflin, Boston.

Gray, B. 1989. Collaborating : finding common ground for multiparty problems, 1st edition. Jossey-Bass, San Francisco.

GWP. 2000. Integrated Water Resources Management. Global Water Partnership.

GWP. 2005. Toolbox Integrated Water Resources Management. Global Water Partnership.

Hooper, B. P. 2005. Integrated River Basin Governance; Learning From International Experiences. IWA Publishing, London.

Hooper, B. P., G. T. McDonald, and B. Mitchell. 1999. Facilitating Integrated Resource and Environmental Management: Australian and Canadian Perspectives. Journal of Environmental Planning and Management 42:747766.

Ison, R. L., P. Steyaert, P. P. Roggero, B. Hubert, and J. Jiggins, editors. 2004. The SLIM (Social learning for the integrated management and sustainable use of water at catchment scale) Final Report.

Klaphake, A. 2005. Kooperation an iunternationalen Flüssen aus ökonomischer Perspektive: Das Konzept des Benefit Sharing. Deutsches Institut für Entwicklungspolitik, Bonn.

Klijn, E.-H., and J. F. M. Koppenjan. 2000. Public management and policy networks; Foundations of a network approach to governance. Public Management 2:135158.

Lamoree, B. 2004. Integrated Water Resources Assessment: A Reassessment by Asit K. Biswas. Water International 29:398-405. 
Leach, W. D., and N. W. Pelkey. 2001. Making Watershed Partnerships Work: A Review of the Empirical Literature. Journal of Water Resources Planning and Management 127:378-385.

Lorraine, W., S. Kean, C. Russell, and M. Peacock. 2005. Connecting Science; What we know and what we don't know about science in society. British Association for the Advancement of Science.

Margerum, R. D. 1999. Integrated Environmental Management: The Foundations for Successful Practice. Environmental Management 24:151-166.

Margerum, R. D., and S. M. Born. 1995. Integrated Environmental Management: Moving from Theory to Practice. Journal of Environmental Planning and Management 38:371-391.

Margerum, R. D., and D. Whitall. 2004. The Challenge and Implications of Collaborative Management on a River Basin Scale. Journal of Environmental Planning and Management 47:407-427.

Massarutto, A., A. De Carli, and C. Longhi. 2004. Public Participation in the Bacchiglione River Basin (Italy). DSE - Università degli Studi di Udine, Udine.

Mitchell, B. 1990. Integrated water management; international experiences and perspectives. Belhaven Press, London.

Mitchell, B. 2004. Integrated Water Resources Assessment: A Reassessment by Asit K. Biswas. Water International 29:398-405.

Mitchell, B. 2005. Integrated water resources management, institutional arrangements, and land-use planning. Environment and Planning A 37:13351352.

Mostert, E. 1999. Perspectives on River Basin Management. Physics and Chemistry of the Earth, Part B: Hydrology, Oceans and Atmosphere 24:563-569.

Mostert, E., E. v. Beek, N. W. M. Bouman, E. Hey, H. H. G. Savenije, and W. A. H. Thissen. 2000. River basin management and planning. Pages 24-55 in E. Mostert, editor. River Basin Management; Proceedings of the International Workshop on River Basin Management (The Hague, 27-29 October 1999). Unesco, Paris.

Nickum, J. E. 2005. Integrated Water Resources Assessment: A Reassessment by Asit K. Biswas. Water International 30:398-405.

Nicol, A. 2003. The Nile: Moving Beyond Cooperation. UNESCO-IHP, Paris. 
Pahl-Wostl, C. 2006. The importance of social learning in restoring the multifunctionality of rivers and floodplains. Ecology and Society 11.

Prins, S., M. Craps, and T. Taillieu. 2006. Boundary Dynamics in Natural Resources Management: the Ambiguity of Stakeholder Inclusion. Revue Gouvernance 2:2-12.

Rees, Y., B. Searle, J. Tippett, and Å. Johannessen. 2005. Good European Practices for Stakeholder Involvement - Lessons from Real Planning Processes; Casestudies and Experiments. WRc plc, Swindon.

Ridder, D., E. Mostert, and H. A. Wolters, editors. 2005. Learning Together To Manage Together; Improving Participation in Water Management. University of Osnabrueck, USF, Osnabrueck.

Sadoff, C. W., and D. Grey. 2002. Beyond the river: the benefits of cooperation on international rivers. Water Policy 4:389-403.

Savenije, H., and P. v. d. Zaag. 1998. The Management of Shared River Basins; Background Paper for the Maseru Conference. Pages 23-69 in H. Savenije and P. v. d. Zaag, editors. The Management of Shared River Basins; Experiences form SADC and EU. Ministerie van Buitenlandse Zaken, Den Haag.

Scheer, S. 1996. Communication between irrigation engineers and farmers; The case of project design in North Senegal. Wageningen University, Wageningen.

Shah, T., I. Makin, and R. Sakthivadivel. 2001. Limits to Leapfrogging: Issues in Transposing Successful River Basin Management Institutions in the Developing World. Pages 89-114 in C. L. Abernethy, editor. Intersectoral management of river basins: Proceedings of an international workshop on "Integrated Water Management in Water-Stressed River Basins in Developing Countries: Strategies for Poverty Alleviation and Agricultural Growth”. International Water Management Institute, Loskop Dam, South Africa.

Tàbara, D., D. Saurí, A. Ribas, C. Bayés, D. Pavon, and J. Maestu. 2004. The Muga River Basin Case Study Catalonia, Spain.

The SLIM Project. 2004. Social Learning as a Policy Approach for Sustainable Use of Water; A field tested-framework for observing, reflecting and enabling. SLIM (Social Learning for the Integrated Management and Sustainable Use of Water at Catchment Scale) Framework. 
Tippett, J., Y. Rees, B. Searle, and C. Pahl-Wostl. 2005. Social Learning in Public Participation in River Basin Management-Early findings from HarmoniCOP European Case Studies. Environmental Science and Policy 8:287-299.

Vansina, L., and T. Taillieu. 1997. Diversity in Collaborative Task Systems. European Journal of Work and Organizational Psychology 6:183-199.

Viessman, W. 1997. Integrated Water Management. Water Resources Update.

Warner, J. F. 2006. More Sustainable Participation? Multi-Stakeholder Platforms for Integrated Catchment Management. Water Resources Development; International Journal of Water Resources Development 22:15-35.

Wenger, E. 1998. Communities of practice : learning, meaning, and identity. Cambridge University Press, Cambridge, U.K. ; New York, N.Y.

World Bank. 1997. Toolkits for Private Participation in Water and Sanitation. International Bank for Reconstruction and Development/ The World Bank, Washington DC.

World Commission on Dams. 2000. Dams and development : a new framework for decision-making. Earthscan, London. 